PATRICK BUCKRIDGE

\section{Gossip and History in the Novels of Brian Penton and Thomas Keneally}

$\mathbf{T}$

The study of gossip as a cultural practice, as distinct from its condemnation as a moral evil, has not long been established; not, at least, outside the boundaries of social anthropology where its key functions in traditional societies have been recognised for some time. Within the last few years, however, gossip has begun to attract interest across a wider front as feminists and others have seen in it a means by which women in patriarchal societies have managed to articulate shared values and experiences, generate group solidarity, and criticise the values of male-dominated cultures.'

These and other new perspectives on gossip have begun to be applied to the study of literature in recent work by Patricia Spacks (1985) and Ross Chambers (1986), both of whom, with somewhat different emphases, have investigated the literary dimensions of gossip in terms of a variety of social functions and effects, including group cohesion, information circulation, ethical boundary-maintenance and moral scapegoating, and competitive personal display. Their analyses draw on English, American and French literature, but gossip is also an obvious and persistent presence in Australian writing, figuring prominently in the work of writers as different in other ways as Patrick White, Thea Astley, Jessica Anderson, Helen Garner, Frank Moorhouse and David Ireland. For the two novelists whose work I wish to discuss here, Brian Penton and Thomas Keneally, gossip seems to have a special importance as a theme, as a formal and stylistic influence, and also as a key term in distinct but comparable conceptions of the role of the historical novelist in Australian culture.

Penton was a journalist for most of his life, mainly with the Sydney Daily Telegraph, where he worked as a reporter, columnist, feature writer and editor. His career coincided with a period in Australian history, in which the related notions of gossip and scandal were invested - at different moments and for different reasons - with enormous political significance. Australian writing and publishing in the 1930s were dogged by a notoriously oppressive moral censorship, and Penton was actively involved, from the late 1920s, in struggles against the censorship of literature and art in both England and Australia. The idea of

' See, for example, Deborah Jones, 'Gossip: Notes on Women's Oral Culture.' Women's Studies International Quarterly 3 (1980): 193-98. scandal was regularly invoked by Penton, Norman and Jack Lindsay, P.R. Stephensen and others to indicate the kinds of effects they were hoping to achieve in their campaigns: 'scandalising' respectable middle-class society by exposing its guilty secrets, telling the tale of its corruption and sterility by insistently refusing discretion in the handling of its private affairs. ${ }^{2}$

There is some confirmation of the positive value Penton placed on gossip and scandal (he makes them synonymous) in one of his regular Telegraph columns as the 'Sydney Spy':

I know that there are some high minded people who do not like sticking their noses into other people's concerns, and giving advice. "When anybody begins talking scandal to me," they say, "I refuse to listen..."

But I have not got a high mind. I love gossip and scandal - the juicier the better. Can you imagine a drearier hole than a world where nobody ever heard any evil, or spoke any evil, or saw any evil? I can't.

Half of the most magnificent literature would be unwritten; history would be as dull as it is taught in schools; Henry VIII, the Queen of Sheba, Gladstone, Pompadour, Bishop Wilberforce, Catherine the Great, and the Kaiser would be as dull and respectable as the heroes and heroines in the novels of Sir Walter Scott - or worse, as dull as they probably were in real life.

For the best gossip transcends mere reporting and enters the refined reaches of creative imagination. If you have two or three really gifted Nosey Parkers in your block of flats life takes on the stirring - if a little crude - excitement of Macbeth recast by the author of East Lynne. (Telegraph 1 August 1934.)

Penton's encomium is obviously not without a certain irony: for one thing the Nosey Parkers whose invention he praises tend to be interchangeable in libertarian demonology with the Mrs. Grundys who complain about dirty books. But inside the defensive circle of ironic disclaimers there is a serious recognition of the imaginative substance and cultural value of the well-told lie. Penton dissolves the conventional barrier between imaginative literature and inventive gossip, leaving it to others - or simply to time - to erect new distinctions less vulnerable to ironic questioning. But in doing so he acknowledges, however obliquely, the 'utopian' impulse objectively present in gossip and scandal. Nor is this a matter only of 'perfecting nature' by fantasy; it may also be, as Spacks suggests, utopian in its adumbration of a true community, intimately bound together by people's interest in one another's lives (Spacks 3-4, 12). Such a millennial vision is registered by the Sydney Spy only to be mocked - but registered nonetheless:

I have to suggest the following as a simple means of solving the pains of the world: Henceforth nobody thinks about how to run his own life, but only what he would do if he were the other man, and the other man does the same, and they follow each other's advice.

${ }^{2}$ For an account of the censorship battles in London in the late 1920s, involving Stephensen, Jack Lindsay, Eric Partridge and other expatriates, see Craig Munro, Wild Man of Letters: The Story of P.R. Stephenson. Melbourne: Melbourne UP, 1985. Chapters 4-7. 
And presto! we have the Millennium!

But no, that can't be right: they've been doing that for the last 50,000 years. (Telegraph

1 August 1934)

Penton was also very keenly aware, however, of the personally destructive power of gossip, especially when motivated by malice, and at different periods of his life he found himself at the receiving end of it. His most memorable depiction of gossip in its destructive mode occurs in his first novel, Landtakers (1934), in the revelation of the secret of Emma's convict past to her husband Derek Cabell, an act of malice that reverberates throughout this novel, and on through its sequel, Inheritors (1936). In an unpublished novel, completed shortly after his arrival in London in 1929, gossip is rather more schematically laid out in its opposing aspects than in the later published novels. This early manuscript, a comic novel about journalists, artists and tycoons in the Sydney of the late 1920 s, makes gossip its central motif. A story of a huge and unexpected legacy is invented by a nondescript middle-aged public servant, Dionysos Blink, and his 'secret' is then variously elaborated and disseminated by three different relays of gossip: Blink's neighbours in Rushcutters Bay, the newspapers, and the international financial community. Finally the fraudulent secret is tracked down and exposed by the 'true' secret (the non-existence of any such legacy) which follows the same channels of transmission as the original lie; but not before the latter has wrought havoc in many people's lives, including that of Blink himself, who escapes to South America just in time to escape retribution.

A thesis of sorts emerges fairly clearly from the design of Penton's early manuscript novel. Firstly, the narrative demonstrates both the destructive and the utopian functions of gossip - its power, that is, to transform given realities in the direction of desire, and to wreck lives, careers, relationships and saving illusions. Secondly, it presents this duality not simply as an intriguing paradox in the nature of things but as a true dialectic, governed by a principle of inexorable forward movement in time in which both self and society will the continual creation and supersession of particular historical states of being. This is familiar Nietzschean doctrine - Penton was heavily influenced by Nietzsche throughout his career - and although the philosopher does not make his presence felt quite as openly here as in the later novels, the fundamental Nietzschean dynamic of 'self-overcoming' is quite clearly and precisely articulated here in terms of the narrative dialectic of gossip that operates throughout (Hergenhan, 'Brian Penton's Thirties Novels' 91-93).

Penton's two published novels, Landtakers and Inheritors, extend the narrative and thematic centring of gossip in interesting ways. In the manuscript novel, the 'secret' of Blink's wealth, though not without some historical dimension there are allusions to the Wall Street Crash - is hardly more than a token object of gossip. Rather more interest attaches to the social practices by which the secret is circulated, the paradigm instance of which (not surprisingly, given Penton's own profession) is the daily newspaper, perceived by Blink as a 'mysterious power...that swept his most intimate whispers to the furthest ears'. ${ }^{3}$ In Landtakers the same dialectic of creation and destruction through gossip is again in evidence; but the central topic is no mere token object, but the classic 'secret' of early Australian social consciousness, the 'convict stain'. This functions in tandem with another conventional object of gossip: concubinage. Derek Cabell, the main protagonist of the novel, lives in a passionate relationship with the silent and strong-willed Emma Surface whom he eventually marries, chiefly to protect his own sexual and social interests from the effects of scandal. Cabell reflects on the matter as follows:

Once this fellow compares notes with the Commissioner it'll be all over the colony that you're living with a woman. Think what talk there'll be at Pat Dennis's then, what Emma will be called. Plainly you couldn't marry a woman they talked about like that, so you'd will be called. Plainly you couldn't marry a woman they talked about like that, so you'd
much better hurry up - before they begin to talk. What's more, you know how bad news travels. Say it got to Cousin Francis's widow in Sydney, and she sent it home to Owerbury. (Landtakers 214)

The scandal of concubinage, then, precipitates one major transformation in Cabell's life, his marriage to Emma; and the scandal of Emma's convict past - unknown to Cabell until her disgruntled cast-off, Black Jem, blurts it out - precipitates another, namely the virtual destruction of their marriage. The first of the two changes (both caused, in effect, by gossip) can be described as 'utopian', both in the personal sense that it promises a future of stable fulfilment for Cabell and Emma, and also in the political sense that the marriage signifies acceptance of the convict heritage as an integral part of a new and vigorous social order, bravely independent of English approval or favour. The second change strips the marriage of its utopian possibilitites and significations. It remains, in formal terms, a marriage; but Cabell's inability to 'forgive' Emma for her past, and her understandable resentment of this, guarantee that their relationship will only ever be a source of mutual torment. But the movement is dialectical, not terminal: from the ruins of their marriage a new and terrible relationship emerges in which each experiences a newly active power of willed self-command. For Emma,

What she had suffered caused her to hate him for not being able to suppress a look of horror and disgust even when he was making love to her; but to trap him into an embrace gave her deepest satisfaction... To make his will a shadow of hers, to outwit the plan of returning to England he treasured so much - this was a dream that poured a warm and balmy oil over her humiliated heart. (237-38)

For Cabell, from that time, 'every triumph over Emma became a triumph over his errant self' (238); their 'painful intimacy' makes it possible for him to overcome his involuntary attraction to the utopian dreams of an Australian

${ }^{3}$ Fryer Library MS (uncat.) 57. The title of the novel is Outrageous Fortune. 
republic which are evoked by Gursey, the transported Irish radical whom he helped to escape:

The covert, cunning spirit of the convict settlement, the degradation of women which he had heard of and imagined among the settlers, the unscrupulous individualism of his fellow expatriates - these he found made flesh in her. He wanted to have them always before his eyes, to remember that this was the essential Australia, so that he would not be tempted to give way to the treacherous stranger in himself, who had listened would not be tempted to give way to the treacherous stranger in himself, who had listened
sympathetically to Gursey's talk about the future, to 'the mob at Pat Dennis's' who pushed aside thoughts of England impatiently and said scandalous things to the Colonel. (238)

The mention of scandal in the last line points again to the dialectical movement of gossip in the novel: by outraging the dignity of rank it gives rise to egalitarian visions of a proud and independent nation, which are then themselves 'scandalised' by gossip about the vice, degradation and self-interest of the less than glorious nation-builders. Emma's secret past falls (however unfairly) into this pattern of scandalous revelation, together with the gossip about Mrs. Peppiott's lechery, her husband's drunken suicide, Mrs. Duffy marching her husband into the settlement to be flogged for his domestic lapses, and Aurelia Darvall giving birth to a black child.

In fact all of these latter instances work as destructive gossip just as effectively, if not more so, in the sequel to this novel, Inheritors, where Cabell himself reanimates them in order to undermine the following generation's attempts to establish itself as a respectable middle class on English lines. Gossip is not always malicious in Penton's novels, but its effects are usually destructive of existing states of affairs, for better or worse. For example, one of the most decisive pieces of gossip in the story of Landtakers carries no intended malice, namely the gossip about Cabell's prosperity and Gursey's gold, but it brings McGovern, the brutal overseer, to Cabell's Reach and thus precipitates the novel's violent conclusion.

Gossip, we might say, operates within the fictional world of Landtakers as a motor of social and personal transmutations, usually of a sudden and unforeseen kind. Indeed, while the bush may be the primary agent of transformation, abrading European complexions, customs and consciences to a new harshness, gossip can be seen as a social mechanism which both complements that transforming power and extends it beyond the direct confrontation with the land into succeeding generations. Gossip is, in other words, a crucial diegetic component of the narrative; but it performs an important rhetorical function as well, organising relations between the text and its readers as well as relations within the text.

The nature of this rhetorical relationship is signalled early in the novel, when the narrator alleges that although 'very little of this story is imaginative', he has nonetheless been largely dependent for information on 'the gossip handed down in the old families of our district' (18). The narrator's epistemological uncertainty reflects and partly accounts for the moral ambivalence of his self-appointed task, which is to scandalise his readers - just as Cabell himself is scandalised, and later scandalises others - by telling them 'secrets' about white Australian society which will destroy myths of a noble pioneering past, and undermine idealistic visions of the future. Such matters as Mrs. Peppiott's adultery with a convict, Mr. Peppiott's drunkenness and suicide, Mrs. Duffy's brutal domination over her husband, and Aurelia Darvall's miscegenation thus form part of a comprehensive negation of nationalist ideologies.

But the rhetoric of Penton's narrative, like the lives of its characters, is dialectical, and within this rhetorical dialectic the moment of negation and disavowal gives rise to its antithesis, a moment of re-acceptance and reengagement. The completion of this movement depends crucially on designating the narrative as gossip, because to do so is to call into play a resistance to negation based on conventional social disapproval of 'gossip-mongering'. The initially scandalised reader, in other words, rises above the narrator's traducements of the Australian spirit, ignoring the disgrace of history in order to concentrate the will for a vigorous reassertion of national pride.

In hypothesising a certain model of 'reader response', I am obviously adopting - and to some extent adapting - the concept of the 'implied reader' elaborated by reader-orientated criticism in recent years (Holub). Where my use of it diverges slightly from some of that work is in seeing 'the reader' as a textual position produced not only by the text (as argued in the work of Wolfgang Iser, for example), but also, in part, by the social context. Specifically, I am suggesting that a 'normative' reading position for Penton's novels was constructed, on their first appearance, out of the complex of social attitudes to gossip and scandal in the popular press, as much as by particular literary strategies in the novels. ${ }^{4}$

One such strategy is worth mentioning though, and that is the device of ' $m i s e$ en abyme', that surprisingly common feature of modern fiction whereby an ideal reader/text relation is analogically represented within the text itself, thus helping to produce the very relation it implicitly reflects (cf. Ron). In this way - and, I would argue, with this effect - the dialectically structured response of Penton's implied reader is mirrored in the lives of several of his characters - not only Cabell and Emma, each of whom achieves an individual triumph of the will over the scandal of Emma's past, but also Ludmilla Darvall, Aurelia's businesslike sister in Landtakers, and Cabell's daughter Harriet in Inheritors, who achieve similar 'self-overcomings'. (By way of contrast, Aurelia, the Colonel and Mrs. Darvall, and Peppiott in Landtakers, and James and Larry Cabell in Inheritors, are destroyed by scandals with which they cannot come to terms.)

${ }^{4}$ By a 'normative' reading position I mean the set of responses that the text seems primarily to assume, or that the writer ('implied author') seems to expect. This neither precludes nor depreciates other possible reading positions, ones involving relations both more and less hostile than the 'norm'; and the historical reception of Penton's novels demonstrates that such positions were certainly taken un . The question of the relationship between 'implied readers' and 'actual readers' is a difficult taken up. I c question of the relatoss it bete beyond observing that the distinction between them would seem to be clopely rotat to that between 'text' and 'context', and to be similarly artity would seem to be closely related to that between 'text' and 'context', and to be similarly arkitrary
- but sometimes useful. 
For the 'implied reader' of Landtakers and Inheritors the analogous progression is one in which national pride, and specifically a belief in the heroic achievements of the pioneers and in the special destiny of Australia, are finally reaffirmed by being scandalised. The heroism needs to be re-imagined in less idealised terms, and the national destiny distinguished from the more simpleminded political fantasies of total national autonomy. But there is no doubt, after all, that Cabell and Emma are pioneer-heroes of a kind; nor, for that matter, is the notion of a special national destiny ever totally dismissed, even if Gursey's radical republican version of it is ridiculed.

At this point, though, a further question arises. If these novels work rhetorically in something like the way I have suggested, do they actually present positive moral and social alternatives for Australia such that a reinvigorated national pride might associate itself with them? It is a question that takes us to the heart of Penton's intellectual dilemma; and once again, gossip provides a key.

All of the main objects of gossip in Landtakers - Emma's convict past, Mrs. Peppiott's adultery, Mr. Peppiott's drunkenness, Mrs. Duffy's marital domination, Aurelia Darvall's miscegenation - have a double aspect. They scandalise 'conventional' morality, both Cabell's and that of the 'implied reader'; but they also have a 'utopian' or speculative aspect, especially when viewed from the perspective of Sydney Bohemian circles in which casual and varied sex, heavy drinking, and pride in the 'convict stain' were taken as signs of a free intellect. In that cultural context, and from the vantage point of the Nietzschean artist who alone creates new values (Nietzsche $55,79,85$ ), the 'scandalous' facts about pioneering society can actually be regarded as harbingers of a new moral order, imagined in terms of the random and fragmentary intuitions of a future in which human pleasure, freedom and power will be untrammelled by stupidity and prejudice. Inevitably, the new order is glimpsed mainly as inversions of existing conventions, suppressions, and prohibitions applied to physical pleasure (the Peppiotts), to the social power of women (the Duffys), and to racial relations (Aurelia Darvall). There is no blueprint here, no programme for a reconstructed society, just the adumbration of some highly transgressive future transformations without which no 'new order' would, in Penton's view, be very new at all.

The importance of gossip in Penton's writing is, I have suggested, closely tied to a dialectical but open-ended conception of national and psychological development through time. Gossip, it emerges, is not merely a trope for the historian's epistemological uncertainty. In virtue of three attributes in particular

5 On Sydney's Bohemian culture in the 1920s, see Jack Lindsay, 'The Roaring Twenties' in Life Rarely Tells. Melbourne: Penguin, 1982; Philip Lindsay, I'd Live the Same Life Over. London: Hutchinson, 1941; Ray Lindsay, A Letter from Sydney. Ed. John Arnold. Melbourne: The Jester Press, 1983. For a very concentrated statement of the libertine ethic, with literary and philosophical trappings, see Penton's Foreword to Jack Lindsay's translation, The Mimiambs of Herondas. trappings, see Penton's Foreword to Jack Lindsay's translation, The Mimiambs of Herondas. and Sydney's Literary Bohemia, 1911-1947.' ALS 11 (1984): 495-502.
- its power of exposure, its unpopularity, and its power to speculate - it is also integrated with the fundamental historical process of making and unmaking, both as an aspect of social behaviour in general and as the basis for a rhetorical strategy by means of which the novelist himself can attempt to become an historical agent in his own time.

While it is important to recognise, with Patricia Spacks and others, the pervasive presence of gossip in human societies, it is also important not to 'universalise' its character and function. Like other cultural phenomena, gossip changes significantly over time - in its typical subject matter, in the socially defined boundaries between gossip and other types of communication, and in the attitudes society adopts towards it. None of these are trans-historical constants, and even within a generation after Penton's novels first appeared, for example, the political and cultural climate in Australia had changed in ways that favoured a slightly different, more positively weighted range of attitudes to gossip and understandings of it. To show something of the historical variation of the gossip-function in Australian fiction it will be useful to look at the work of Thomas Keneally, in whose novels gossip seems to function less as an instrument of iconoclastic exposure and provocation, or even as a means of prophetic imagining - it has both these functions in Penton's work - than as a system of unofficial communication, a means of group solidarity and a form of popular resistance.

Even in Keneally's earliest novels it is clear that gossip, rumour and scandal are not just part of 'what happens' in the novel, but of what the novel means. In Bring Larks and Heroes (1967), for example, various 'secrets' - Halloran's engagement to Ann and the planned rebellion, most notably - are gossiped about in various quarters of the penal community, and the logic of the narrative suggests, by a multitude of specific causalities, not that this is a problem (Halloran's condemnation of scandal-mongering notwithstanding), but that, on the contrary, such activity significantly ameliorates the severity of the System.

The always-implicit 'praise of gossip' is repeated several times in the novels that follow Bring Larks and Heroes, always in highly situation-specific terms, and usually with some reminders of its ethically dubious characteristics. The gossip about Leeming's death in The Survivor (1969), for example, is sordid and, as it transpires, false; but it is what motivates the expedition that recovers the body. The brother and sister in A Dutiful Daughter (1971) are oppressed by the constant fear of gossip about their parents' bovine transmutation, but it is finally only by spreading the secret abroad that the daughter can gain her freedom. Similarly, in Blood Red, Sister Rose (1974), Jeanne fears and is hurt by gossip that represents her as a witch and a whore; yet it is partly by the calculated orchestration of gossip about Jeanne's anatomy and sexuality that Yolande, the worldly French queen, is able to secure Jeanne's power and safety for as long as she does.

In The Chant of Jimmie Blacksmith (1972) the pattern is complicated 
somewhat by the presence of two distinct relays of gossip: the one that operates within the Aboriginal community, both as a system of communication and as an instrument of mythmaking; and the one within white society, which also transmits information and creates legends - in this case the 'legend' of a crazed and bloodthirsty savage, which literally overtakes and destroys the legend of the noble warrior celebrated in his brother Mort's chant. Jimmie is isolated from both these information circuits, and suffers accordingly: in the spiritual and cultural deprivation caused by his exclusion from Aboriginal gossip; and in other ways by his lack of access to the white gossip about Gilda which, rightly or wrongly, would certainly have stopped him from marrying her.

In The Chant, gossip may also be operating as a kind of authorial 'modesty trope'. The narrator is presented, implicitly, as something of a gossip himself, a person whose attitudes and opinions on the events of the story serve mainly to signify a sense of historical limits, a sense that when confronted by a tragic anomaly like Jimmie Blacksmith the most well-intentioned commentator can only understand what his culturally given categories make visible or comprehensible at a particular moment in history. ${ }^{6}$ The understanding that such a novel achieves is offered to history, in Derrida's phrase, 'under erasure'; and the sign of its anticipated supersession is precisely its implied affiliation with gossip. What makes it worthwhile for a writer like Keneally to lay his credibility on the line, exposing himself to the later ridicule or censure of posterity, is the possibility that some fact or perspective which may seem merely bizarre or scandalous in the terms for synthesis accessible to the writer will prove to be a crucial element in a future synthesis, to which the writer, at the time of writing, has no access.

This rationale is only implicit in The Chant of Jimmie Blacksmith. Three years later, in Gossip from the Forest, the related conceptions of the writer as gossip and the writer as historical actor are more fully and explicitly worked out. In an interview published in that year, Keneally claimed to be neither an historian nor a 'strict historical novelist'. He wishes 'to find evidence in earlier events for the kind of society we have now', and insists that 'the only warrant a novelist needs for his ideas about the past is that they reek of human, poetic, dramatic, symbolic veracity and resound in his imagination'. They are thus 'in some ways the worst historians. But there are some ways in which some of them, not all but a few, might turn out to be the best historians of all' (Keneally, 'Doing Research' 27; my emphasis).

${ }^{6}$ Henry Reynolds, in his powerful essay 'Jimmy Governor and Jimmie Blacksmith', ALS 9 (1979): 14-25, regards the elements of racist ideology in the novel, in particular the retailing of white myths of Aboriginal violence and promiscuity 'in the blood', as attributable to Keneally himself, as a fairly typical representative of well-intentioned but ill-informed late 1960s liberalism. I disagree with Reynolds, but not to the extent of claiming that there is a whole other, more enlightened with Reynolds, but not to the extent of claiming that there is a whole other, more enlightened set of racial attitudes present in the novel, even implicitly, to which the narrator's attitudes are ironically counterposed. Iargue merely that the narrator's attitudes are ironically distanced or
brackethout any clear alternative implied.
In the novel professedly written according to these premises, Gossip from the Forest, gossip is for the first time an explicit and central theme, closely articulated with all the other major issues the novel deals with, and inseparable from its formal and stylistic strategies. It is a novel that repays fairly detailed examination.

The gossip theme, already evident in the title, is introduced into the narrative proper at an early stage when the narrator stipulates that the account the novel presents 'is not scholarly but merely gossip from the forest': the truth about Marshal Foch, as about other historical characters and events, 'will be found haphazardly in these pages' (Gossip 26-27). The random distribution of 'truth' through the facts, anecdotes, speculations and rumours surrounding the signing of the Armistice is a given condition of the situation, to be accepted and negotiated by novelist, participant and reader alike: by the novelist as he tries to make sense of the contradictory or merely non-committal sources at his disposal; by the participants, Matthias Erzberger and the rest, as they try to get their bearings in an environment where 'all the links of coherence and arrangement were shrivelling apart' (88); and by the reader as she or he grapples with the unprecedentedly gossip-like design of the narrative, consisting as it does of a hundred-odd sections (or 'snippets') varying widely in length, mode, subject matter and unity, guided only by section titles (e.g. 'Is It Something Physical?', 'Off To See the Frocks') that generally provide little or no indication of thematic priorities or wider contexts of understanding. ${ }^{\text {? }}$

Gossip is also a more prominent diegetic element than usual. It is there both as a communications system, the only one remaining in a physically devastated Europe, and as an instrument of personal (and therefore political) power to which both of the leading negotiators sometimes resort as a means of establishing their authority - Foch mainly over the British delegates, and Erzberger over his recalcitrant colleagues on the German side.

Apart from these functions though, gossip becomes, in its various forms legend, anecdote, family secret, scandal, rumour - a prime object of thematic interest in the novel, not by explicit analysis or discussion, but by its implicit intersections with a range of thematic antinomies: public and private, part and whole, death and life, truth and falsehood, past and present, present and future. In relation to each of these gossip is presented as performing a 'reconstructive' function, which involves both connecting and balancing the two sides of the antinomy. I shall examine just the first of these thematic antinomies, that of public and private, to indicate how the reconstructive function of gossip seems to work on all of them.

The public/private antinomy is especially important, since one of the implicit theses of the novel is that the horrors of the Great War were made possible by a deep split between the public and private spheres of European society, such

On the diegetic level, Keneally has spoken of characters like Erzberger as 'men fighting historic causes on which they can't quite get a grip'. (Hergenhan, 'Interview' 454). 
that politicians, bureaucrats and generals were able to decide and act exclusively in terms of public entities such as nations, armies and navies, physically and imaginatively insulated from the private interests and personal suffering of millions of individuals. Part of what Erzberger is trying to achieve when, in the course of negotiation, he retails his 'haphazard' impressions of civilian malnutrition and demoralisation in Germany is to enable the British delegates to imagine the private dimensions of their naval blockade. That his stories of chaos and famine are finally dismissed as lies (204), even by the well-intentioned Admiral Wemyss, signals his failure to bridge the gap between the two perspectives.

Another illustration of gossip's relation to the public/private opposition is the episode in which Wemyss sees two old women on the platform, literally 'gossiping' in the traditional sense:

One nattered, the other nodded, nodded, nodded. Telling and heeding some eternal woman's story: first he says he loves and must have you, then you bud with children and he's off with low women, so next you're both old and veins show and he dies of his excesses and your womb is shrunken to a split pea and your sons' sons are imperilled in strange wars. (74-75)

Their gossip is a discourse in which private and public experience $\leftarrow$ family life and war - interpenetrate easily and without incongruity; and it is appropriate that the utopian fantasy Wemyss indulges at this point is of sharing the burden of his public (i.e. official) identity and mission with the private people around the train, thereby producing a miraculous regeneration of health and well-being:

If those people knew what this train was for the lame man would walk straight, the old women hug and dance quaint measures... It would be Breughel stuff. (75)

Gossip and scandal can override the boundary between the public and private spheres, in both directions. If Erzberger's purpose in gossiping with the Allied delegates is to make them 'imagine the private' sufficiently to mitigate the ruthlessness of their terms, the task he undertakes with his own delegates is to scandalise them out of their insulated private worlds, to make them 'think public' sufficiently to argue their case effectively. Maiberling, for example, has to be shamed into realising that 'we're not private men now' (69) and cannot afford to pursue personal obsessions. Like Vanselow, who cannot understand why the public fact of his French wife's nationality should have destroyed the bliss of his private relationship (82), he has to be made aware of the power of scandal, and must moderate his private life to reduce his vulnerability to public attack, as Erzberger had to do early in his political career (124). ${ }^{8}$

${ }^{8}$ Keneally has later observed that Erzberger 'has a sense of being the only one there who can forese the ultimate results for Europe in what is happening in that railway carriage'. (Hergenhan 'Interview' 454).
But if Erzberger represents the reconstructive effects of reconnecting and rebalancing the two spheres, Marshal Foch represents the danger of erasing the distinction altogether. He embodies not so much a reconciliation of the antinomy, as its complete annihilation: 'He was that freak: the man whose private and public selves were one' (18)

For 'The Marshal', as he is invariably called, public identity does not conflict with private impulses but is coextensive with them, and in this he differs from all the other delegates at the table. His personality constitutes itself entirely in the public domain of the French national tradition and destiny. His friendship with General Weygand is conceived by him entirely in these terms: in the chapel at the Hôtel-Dieu, the Marshall reflects on 'the continuity of French things' and, with Weygand sitting at his side, thinks 'this isn't the rootless brotherhood Clemenceau feels for his callisthenist. This is Roncevalles brotherhood. I am a very fortunate man' (197). Even his biological rhythms are attuned, mysteriously, to the exigencies of his public service: he has missed only two full nights' sleep in the course of the war: once during an offensive on the Marne in September 1914, when he was informed of his elevation to Grand Officer of the Legion of Honour, and he sat up quietly celebrating while 'all communications were being brought to us' and, emblematically, 'our bedroom became an army group HQ' (100).

The private/public relation, in other words, is as disturbed in Foch as it is in most of the other delegates, but in a different way. Where the latter reflect in their personalities the destructive split in European ruling-class consciousness at the time of the Great War, the Marshall's personality anticipates, rather, the totally corporatised private individual of fascist ideology. Gossip can neither shame nor humanise such a mentality; all it can do (as Schindler later found) is build escape routes from it.

To take a final connection, in a terse (and gossipy) epigraph to the nove Keneally observes, 'In the season in which this book was written, the French government persisted in exploding nuclear devices above the ocean where my children swim.' The reference, of course, is to the French nuclear test series at Muroroa Atoll in 1974, conducted in the teeth of protests by the Australian and New Zealand Labour governments and widespread popular opposition in the region. To say that two such widely separated events as Muroroa and the Armistice are being proposed as parallel instances of an arrogant and myopic French chauvinism would no doubt be too crude, but the juxtaposition is, I believe, no more 'haphazard' than the main narrative.

The epigraph can be read as a device that yokes the public domain of international diplomatic wrangling, defence strategy and colonial policy, to the private domain of family relations and personal lifestyles, insisting on a mutuality of obligations between the two domains but leaving their separate existence and prerogatives intact. Literally, the epigraph epitomises this strand in the novel's thematic pattern; and similar arguments could be made with regard to other 
strands not dealt with here, in particular the temporal antinomies of past, present and future (in the cyclical connotations of 'season' in the epigraph), and the spatial antinomies of part and whole (in the significant physical unity of the Pacific Ocean). Obviously Gossip from the Forest is not 'about' Muroroa, but it does function, nonetheless, as a sort of obliquely-angled gossip about it a hubbub of voices from the forest of the past whose anecdotes, speculations, premonitions and hypotheses about their own crisis provide (among other things) a source of subversive scandal concerning the past behaviour of French politicians, which an enterprising anti-nuclear activist in 1975 might well have found politically useful.

Gossip from the Forest is Keneally's most complex study of gossip both as an historical force in its own right, and as a paradigm for the novelist's unpredictable and opportunistic power to intervene in the course of history. This novel's acknowledged connection to a specific political crisis draws out the implications of both these aspects more fully than any of his earlier or later work. But gossip has remained a constant preoccupation for Keneally, and later novels such as Cut-Rate Kingdom (1980), Schindler's Ark (1982) and A Family Madness (1985) extend his analysis of its mainly beneficent power in a variety of social and historical contexts.

In considering the uses and significance of gossip in the work of Penton and Keneally we have noticed rather different emphases being placed on its positive and negative aspects. In Penton the destructive, disillusioning functions of gossip are always paramount: they are used, primarily, as a cathartic preparation for the creation of a vital new social order, the features of which are only occasionally insinuated by gossip in its speculative function. In Keneally the destructive aspect of gossip is always secondary. Although its ambivalence is carefully acknowledged in his most comprehensive novelistic treatment of it, Gossip from the Forest, the general emphasis in most of his novels is on gossip as a beneficent and potentially emancipatory activity, a form of social interaction and communication outside the restrictions of official channels, and a way of probing for possibilities beyond the historical boundaries of rational prediction and projection.

The reasons for this difference of emphasis are no doubt partly temperamental, but they are also partly historical. Penton's novels were written in the mid 1930s, a period which Penton, among others, perceived as being dominated by conservatism, complacency and moral repression. ${ }^{9}$ Keneally, on the other hand, was writing in the late 1960s and early 1970s in the midst of significant liberal advances on issues such as censorship and sexual morality, Aboriginal rights, and arms control - all issues which are manifestly relevant to his work in these years. In his fictional deployments of gossip, accordingly, Keneally seems to place his writing in a kind of cooperative alignment with the socially and politically progressive momentum of Australian consciousness at that time. His implied

9 For the fullest elaboration of Penton's analysis of the pre-War decade see his Advance Australia - Where?. London: Cassell, 1943. 1-64. reader is a liberal-progressive like himself with whom he shares a close, confidential, at times even conspiratorial, relationship. Penton, by contrast, used gossip, both in his novels and in his journalism, to construct an antagonistic relation to what he saw as the complacent conservatism of Australian culture. His implied reader is, accordingly, a main target of his critique, namely a decent and respectable patriot whose decency, respectability and patriotism Penton delights to offend and scandalise, and who may just possibly, as a consequence, catch glimpses of a very different Australia from the one he knows. Differences of tone and emphasis notwithstanding, gossip is an important element in the work of both these writers, if only because it has been a means of giving them, as historical novelists, some real purchase on the formation of Australian political and cultural values in their own times.

Works Cited

Chambers, Ross. 'Gossip and the Novel: Knowing Narrative and Narrative Knowing in Balzac, Mme. de Lafayette and Proust.' Australian Journal of French Studies 23 (1986): 212-233. Tergenhan, Laurie. 'Brian Penton's Thirties Novels: The "Roots of the New Psyche", Unnatural Lives: Studies in Australian Fiction about the Convicts. St Lucia: University Unnatural Lives: Studies in Australia

'Interview with Thomas Keneally.' Australian Literary Studies 12 (1986): 453-57.

Holub, Robert. Reception Theory: A Critical Introduction. London: Methuen, 1984.

Keneally, Thomas. Bring Larks and Heroes. Melbourne: Sun Books, 1967.

The Chant of Jimmie Blacksmith. Melbourne: Fontana, 1978.

'Doing Research for Historical Novels.' The Australian Author 7.1 (1975): 27-29. . Gossip from the Forest. Kent: Coronet Books, 1975.

Nietzsche, Friedrich. Thus Spoke Zarathustra. Trans. R.J. Hollingdale. Harmondsworth Penguin Books, 1967.

Penton, Brian. Advance Australia - Where?. London: Cassell, 1943

. Landtakers: The Story of an Epoch. Sydney: Angus and Robertson, 1972.

Reynolds, Henry. 'Jimmy Governor and Jimmie Blacksmith.' Australian Literary Studies, 9 (1979): 14-25.

Ron, Moshe. 'The Restricted Abyss: Nine Problems in the Theory of Mise en Abyme.' Poetics Today 8.2. (1987): 417-38.

Spacks, Patricia Meyer. Gossip. New York: A.A. Knopf, 1985. 